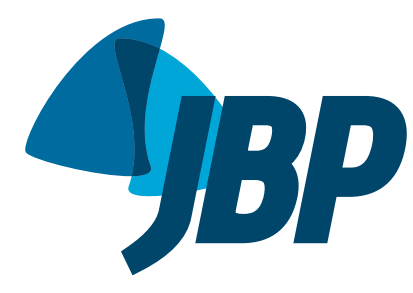

1. Serviço de Pneumologia, Centro Hospitalar de São João EPE, Porto, Portugal.

2. Instituto de Investigação em Ciências da Vida e Saúde - ICVS -, Escola de Ciências da Saúde, Universidade do Minho, Braga, Portugal.

3. Laboratório Associado ICVS/3B's, Instituto de Investigação em

Ciências da Vida e Saúde e Grupo de Investigação em Biomateriais, Biodegradáveis e Biomiméticos, Braga/ Guimarães, Portuga

4. Serviço de Radiologia, Centro Hospitalar de São João EPE, Porto, Portugal.

5. Faculdade de Medicina, Universidade do Porto, Porto, Portugal.

Submitted: 14 June 2015.

Accepted: 4 November 2015

Study carried out at the Serviço de

Pneumologia, Centro Hospitalar de São JoãoEPE, Porto, Portugal.

\section{Influence of emphysema distribution on pulmonary function parameters in COPD patients}

\author{
Helder Novais e Bastos ${ }^{1,2,3}$, Inês Neves' ${ }^{1}$, Margarida Redondo', Rui Cunha ${ }^{4,5}$,
} José Miguel Pereira ${ }^{4,5}$, Adriana Magalhães', Gabriela Fernandes ${ }^{1,5}$

\begin{abstract}
Objective: To evaluate the impact that the distribution of emphysema has on clinical and functional severity in patients with COPD. Methods: The distribution of the emphysema was analyzed in COPD patients, who were classified according to a 5-point visual classification system of lung CT findings. We assessed the influence of emphysema distribution type on the clinical and functional presentation of COPD. We also evaluated hypoxemia after the six-minute walk test $(6 \mathrm{MWT})$ and determined the six-minute walk distance (6MWD). Results: Eighty-six patients were included. The mean age was $65.2 \pm$ 12.2 years, $91.9 \%$ were male, and all but one were smokers (mean smoking history, 62.7 \pm 38.4 pack-years). The emphysema distribution was categorized as obviously upper lung-predominant (type 1), in $36.0 \%$ of the patients; slightly upper lung-predominant (type 2), in 25.6\%; homogeneous between the upper and lower lung (type 3), in 16.3\%; and slightly lower lung-predominant (type 4), in 22.1\%. Type 2 emphysema distribution was associated with lower FEV $1, F V C, F E V$, FVC ratio, and DLCO. In comparison with the type 1 patients, the type 4 patients were more likely to have an $F E V_{1}<65 \%$ of the predicted value $(\mathrm{OR}=6.91,95 \% \mathrm{Cl}: 1.43-33.45 ; \mathrm{p}=0.016)$, a $6 \mathrm{MWD}<350 \mathrm{~m}(\mathrm{OR}=$ $6.36,95 \% \mathrm{Cl}: 1.26-32.18 ; \mathrm{p}=0.025)$, and post-6MWT hypoxemia (OR $=32.66,95 \%$ $\mathrm{Cl}$ : 3.26-326.84; $p=0.003$ ). The type 3 patients had a higher RV/TLC ratio, although the difference was not significant. Conclusions: The severity of COPD appears to be greater in type 4 patients, and type 3 patients tend to have greater hyperinflation. The distribution of emphysema could have a major impact on functional parameters and should be considered in the evaluation of COPD patients.
\end{abstract}

Keywords: Pulmonary disease, chronic obstructive; Pulmonary emphysema; Respiratory function tests; Tomography, X-ray computed.

\section{INTRODUCTION}

The lung disease known as COPD is characterized by persistent airflow limitation that is usually progressive, consisting of a combination of small airways disease (obstructive bronchiolitis) and parenchymal destruction (emphysema). (1) There is increasing evidence to suggest that distinguishing different phenotypic profiles of patients with COPD has prognostic and therapeutic implications. ${ }^{(2-4)}$ In fact, COPD patients with confirmed emphysema have more severe lung function impairment, more intense airway inflammation, and possibly more important extrapulmonary disability than do those without emphysema. ${ }^{(2,5,6)}$ The lung hyperinflation caused by the loss of lung elastic recoil has been associated with limitations in the functional capacity of these patients. . $^{(7,8)}$ In addition, the destruction of the alveolar-capillary membrane in emphysema is responsible for more profound hypoxemia. ${ }^{(9)}$

Advances in CT scanning and image processing software have allowed the precise measurement of the extent of low-attenuation areas corresponding to emphysema. In validation studies, the results obtained with these techniques have been found to correlate well with pathologic and functional features. ${ }^{(10-13)}$ This kind of assessment has been mainly used in order to evaluate patients for lung volume reduction procedures and to monitor replacement therapy in alpha-1 antitrypsin-deficient patients. ${ }^{(14-16)}$ However, quantifying emphysema might have broader utility, given that some reports have shown that the heterogeneity of the distribution of parenchymal damage might be associated with different degrees of clinical severity. ${ }^{(13,17-19)}$ Nevertheless, the results are contradictory, which might be attributable to the different methods that have been used in those analyses. The majority of authors have employed computer-assisted measurements, which are expensive and not widely available. In order to promote a definitive widespread use of imaging data in the clinical evaluation of patients with emphysema, we believe that there is also a need to standardize qualitative methods.

The aim of the present study was to evaluate the impact that the distribution of emphysema has on clinical and functional features in COPD patients. In order to test our hypothesis, we used a visual classification system to categorize patients according to the regional distribution of their emphysema. 


\section{METHODS}

\section{Study subjects}

This was a cross-sectional observational study involving COPD patients with emphysema, recruited between August of 2011 and August of 2012 from the pulmonology outpatient clinic of the Centro Hospitalar de São João, a tertiary care medical center located in the city of Porto, Portugal. We included patients with pulmonary emphysema and any degree of airflow limitation who had been clinically stable in the 3 months prior to their inclusion in the study. The inclusion criteria were having a post-bronchodilator $\mathrm{FEV}_{1} / \mathrm{FVC}$ $<0.70$ and showing evidence of emphysema on visual inspection of CT images, estimated to involve $>25 \%$ of the lung parenchyma. ${ }^{(20)}$ Patients with a history of asthma, bronchiectasis, tuberculosis sequelae, lung fibrosis, thoracic surgery, or other confounding diseases were excluded (Figure 1). The study was approved by the local research ethics committee, and all patients gave written informed consent.

\section{Clinical and pulmonary function assessment}

We recorded demographic and anthropometric data, namely age, gender, and BMI. ${ }^{(21)}$ Patients also underwent clinical evaluation, which included the completion of the COPD Assessment Test (CAT) and the modified Medical Research Council (mMRC) scale (for the determination of dyspnea severity), ${ }^{(22)}$ as well as the evaluation of smoking status (current smoker, former smoker, or nonsmoker), smoking history (in pack-years), the presence of significant comorbidities, and current medication use. The number of COPD exacerbations in the last year ${ }^{(23,24)}$ was retrospectively obtained by patient recall, and, in most cases, hospital records were used in order to corroborate the information. Each patient was submitted to spirometry (MasterScreen ${ }^{\mathrm{TM}}$ Body; Jaeger, Würzburg, Germany), lung volumes and DLCO also being determined, in accordance with international guidelines. ${ }^{(25,26)}$ The six-minute walk test (6MWT) was performed using the methodology described by the

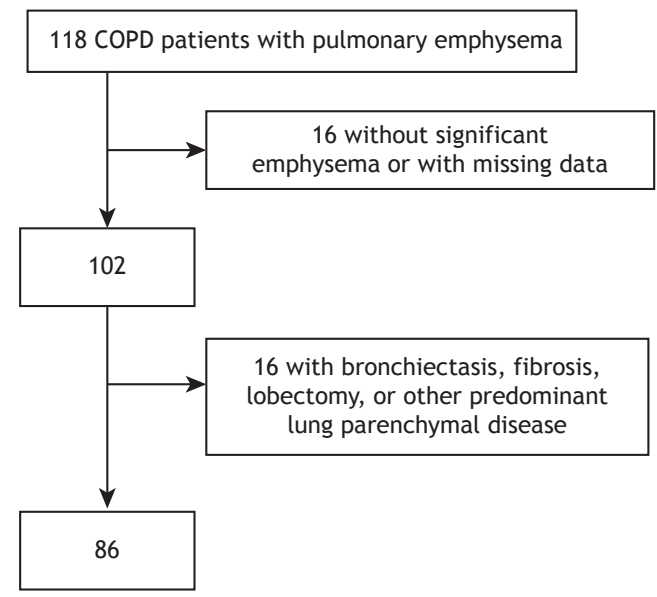

Figure 1. Flowchart for the selection of the participating patients.
American Thoracic Society. ${ }^{(27)}$ Arterial blood gases were measured (RapidLab ${ }^{T M}$ 1265; Siemens, Munich, Germany) after a minimum 30-min rest period in a sitting position. We defined hypoxemia as a $\mathrm{PaO}_{2}<$ $60 \mathrm{mmHg}$ at an $\mathrm{FiO}_{2}$ of 0.21 .

\section{CT evaluation}

All patients underwent multidetector CT of the chest at suspended full inspiration, from the thoracic inlet to the adrenal glands, using a 64-detector row scanner (Somatom Sensation 64; Siemens Healthcare, Erlangen, Germany). The following imaging parameters were used: tube voltage, $120 \mathrm{kVp}$; tube current, $40 \mathrm{mAs}$; rotation time, $0.33 \mathrm{~s}$; pitch, 1.3 ; detector collimation, $32 \times 0.6 \mathrm{~mm}$; and slice acquisition by means of a z-flying focal spot, $64 \times 0.6 \mathrm{~mm}$. No contrast media were used. From the raw data, $1 \mathrm{~mm}$-thick sections were obtained using a soft tissue kernel reconstruction (B50f; Siemens Healthcare). For the subjects submitted to multiple CT scans, the one performed the closest to study enrollment was used.

Two thoracic radiologists independently reviewed the CT imaging studies. Both were blinded to the clinical information of the patients. Disagreement between the two radiologists was resolved by consensus. They reviewed CT images on the coronal and sagittal planes to assess the heterogeneity of emphysematous changes in an apical-to-caudal direction. For image interpretation, we used a window level of -700 to $-900 \mathrm{HU}$ and a window width of $600-1,600 \mathrm{HU} \cdot{ }^{(28)} \mathrm{A}$ five-point visual classification system was applied, as previously described. ${ }^{(18)}$ This qualitative evaluation ranks pulmonary emphysema according to its predominant distribution, as follows: type 1 , obviously predominant in the upper lung; type 2, somewhat predominant in the upper lung; type 3, equal extent in the upper and lower lung (homogeneous distribution); type 4, somewhat predominant in the lower lung; and type 5 , obviously predominant in the lower lung.

\section{Statistical analysis}

Variables with normal distribution are expressed as means and standard deviations, whereas those with non-normal distribution are expressed as median and interquartile range (25th to 75th percentile) and categorical variables are expressed as absolute values and proportion. The Student's t-test for independent samples was used in order to compare variables with normal distribution, and the Mann-Whitney $U$ rank test was used in order to compare variables with non-normal distribution. The Pearson's chi-square test was used for categorical variables. One-way ANOVA was used in order to compare the emphysema distribution groups, together with Tukey's post hoc test to identify significant differences. Odds ratios and the corresponding 95\% confidence intervals were calculated using binary logistic regression. Odds ratios were adjusted for age and BMI. Statistical significance was set at $p<0.05$ (two-tailed), and all statistical analyses were performed with the SPSS Statistics software package, version 19.0 (IBM Corporation, Armonk, NY, USA). 


\section{RESULTS}

During the study period, 86 COPD patients with pulmonary emphysema were selected, the characteristics of whom are shown in Table 1. Male gender was predominant in this population, all but one of the patients were current or former smokers, and 1 patient presented with homozygous PiZZ alpha- 1 antitrypsin deficiency. The CAT scores indicated severe symptoms more often than did the mMRC dyspnea scale scores: $56.1 \%$ of the patients had CAT scores $\geq 10$, whereas only $40.8 \%$ had mMRC scale scores $\geq 2$. Only $24.4 \%$ of the patients had frequent exacerbations ( $\geq 2$ exacerbations in the last year). Hypoxemia was present in 15 patients (18.8\%). The characteristics of the patients demonstrated a wide range of airflow limitation, with an even distribution across the Global Initiative for Chronic Obstructive Lung Disease severity classification, ${ }^{(1)}$ which is based on $\mathrm{FEV}_{1}$-mild, in $27.9 \%$; moderate, in $22.1 \%$; severe, in $29.1 \%$; and very severe, in $20.9 \%$-reflecting the spectrum of the disease encountered in clinical practice. However, there was a clear tendency for hyperinflation to be seen in this group of patients, with a median residual volume/total lung capacity (RV/TLC) ratio of $55.5 \%$ and a significant median oxygen desaturation during the $6 \mathrm{MWT}$ of $6 \%$.

In most $(36.0 \%)$ of the patients, the emphysema was obviously predominant in the upper lung (type 1 distribution). The next most common distributions were types 2 and 4 (somewhat predominant in the upper lung and somewhat predominant in the lower lung, seen in $25.6 \%$ and $22.1 \%$ of the patients, respectively). Type 3 emphysema distribution (homogeneous distribution between the upper and lower lung) was the least common, seen in only $16.3 \%$. None of the patients in our sample were classified as presenting with type 5 emphysema distribution (obviously predominant in the lower lung). The interobserver correlation for emphysema classification scores was good $\left(r_{s}=0.621, p<0.001\right)$

Figure 2 shows the differences found in the clinical parameters according to CT scan classification of emphysema distribution. The six-minute walk distance (6MWD), post-6MWT oxygen desaturation, FVC, FEV $_{1}$, and $\mathrm{FEV}_{1} / \mathrm{FVC}$ ratio (in \% of the predicted values), as well as DLCO, were found to differ significantly among the groups. Tukey's post hoc test revealed that there were significant differences in all of the abovementioned variables between the patients classified as type 1 than those classified as type 4. In fact, all of those variables appear to get worse in upper-to-lower predominance direction. Patients classified as type 3 showed the highest RV/TLC ratio, although it did not reach statistical significance $(p=0.064)$.

The logistic regression analysis for different dimensions of the functional status revealed that type 4 patients had a significantly higher risk for having

Table 1. Demographic, clinical, and imaging characteristics of selected patients with emphysema-predominant COPD. ${ }^{a}$

\begin{tabular}{|c|c|}
\hline Characteristic & $(n=86)$ \\
\hline Age,years & $65.2 \pm 12.2$ \\
\hline \multicolumn{2}{|l|}{ Gender } \\
\hline Male & 79 (91.9) \\
\hline Female & $7(8.1)$ \\
\hline $\mathrm{BMI}, \mathrm{kg} / \mathrm{m}^{2}$ & $23.1 \pm 4.5$ \\
\hline Smoking history, pack-years & $54(38-79)$ \\
\hline mMRC dyspnea scale score & $1(0.5-3.0)$ \\
\hline mMRC dyspnea scale score $\geq 2$ & $35(40.8)$ \\
\hline CAT score & $12(7.0-22.5)$ \\
\hline CAT score $\geq 10$ & $48(56.1)$ \\
\hline Exacerbations in the last year & $1(0-2)$ \\
\hline$\geq 2$ exacerbations in the last year & $21(24.4)$ \\
\hline Hypoxemia & $15(18.8)$ \\
\hline Post-6MWT desaturation, $\%$ & $6(4.0-9.8)$ \\
\hline 6MWD, m & $400(256.3-463.8)$ \\
\hline FVC, $\%$ of predicted & $86.1 \pm 24.8$ \\
\hline $\mathrm{FEV}_{1}$ & $50.0(32.0-83.3)$ \\
\hline $\mathrm{FEV}_{1}^{1} / \mathrm{FVC}$ ratio & $45.9(35.0-63.2)$ \\
\hline RV & $162.0(125.1-225.0)$ \\
\hline TLC & $118.3 \pm 24.4$ \\
\hline RV/TLC ratio & $55.5(43.9-67.1)$ \\
\hline DLCO & $59.0(40.0-77.7)$ \\
\hline \multicolumn{2}{|l|}{ Emphysema distribution } \\
\hline Type 1 (obvious upper-lung predominance) & $31(36.0)$ \\
\hline Type 2 (slight upper-lung predominance) & $22(25.6)$ \\
\hline Type 3 (equal upper- and lower-lung extent) & $14(16.3)$ \\
\hline Type 4 (slight lower-lung predominance) & $19(22.1)$ \\
\hline
\end{tabular}

mMRC: modified Medical Research Council; CAT: COPD Assessment Test; 6MWT: six-minute walk test; and 6MWD: six-minute walk distance. a Values are presented as mean $\pm S D, n(\%)$, or median (interquartile range). 
$\mathrm{FEV}_{1}<65 \%$ of the predicted value (adjusted OR $=$ 6.92; 95\% CI: $1.43-33.45 ; \mathrm{p}=0.016), 6 \mathrm{MWD}<350$ $\mathrm{m}$ (adjusted OR $=6.36 ; 95 \% \mathrm{CI}: 1.26-32.18 ; \mathrm{p}=$ 0.025 ), and hypoxemia (adjusted OR $=32.66 ; 95 \%$ CI: 3.26-326.84; $p=0.003$; Table 2). However, none of the different types of emphysema distribution were found to be significant predictors of BMI $\leq 21 \mathrm{~kg} / \mathrm{m}^{2}, \geq$ 2 exacerbations in the last year, mMRC dyspnea scale score $\geq 2$, or post-6MWT oxygen desaturation $\geq 4 \%$.
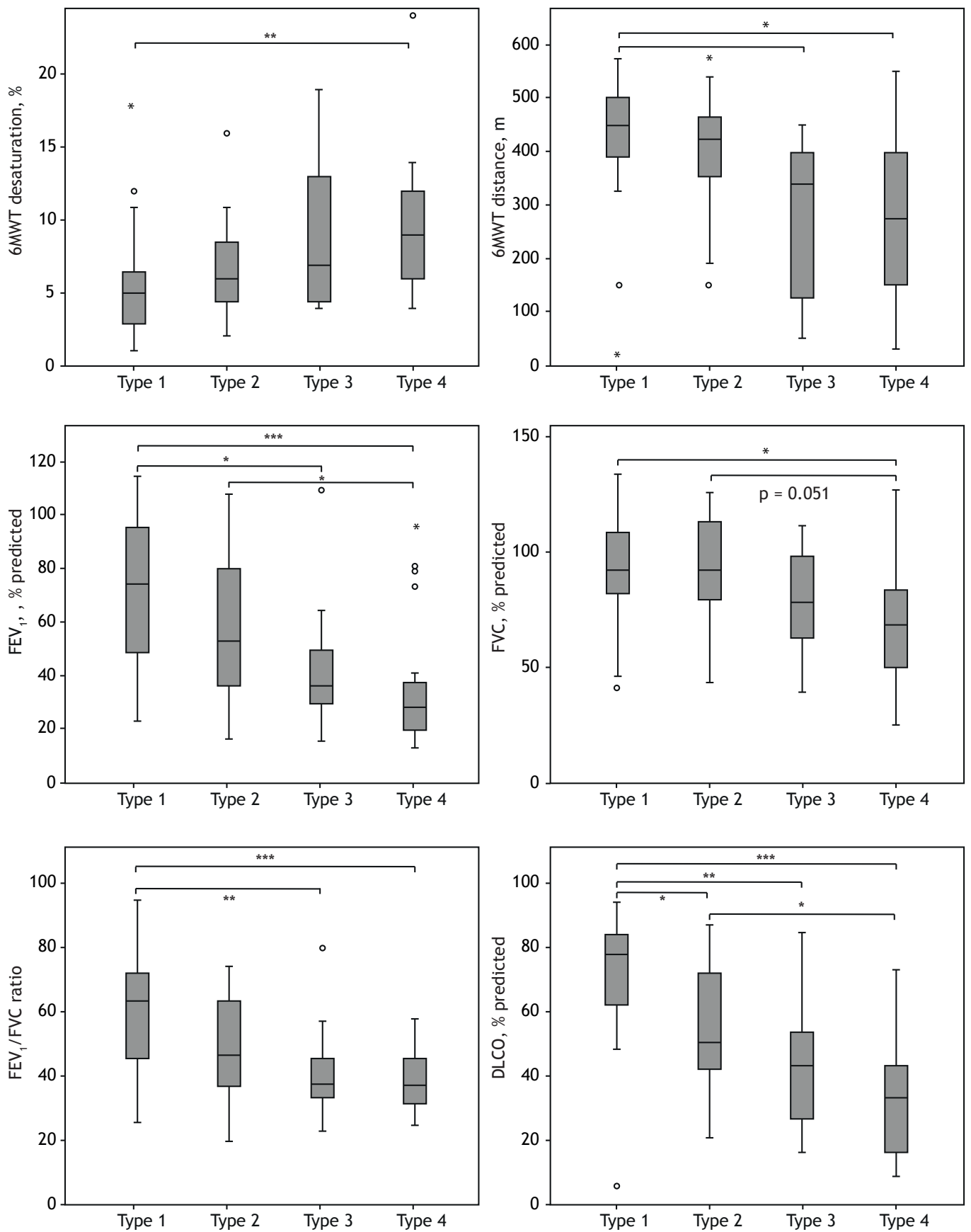

Figure 2. Lung functional characteristics of patients with different emphysema distribution. *Indicates a $p$ value $<0.05$ 6MWT: six-minute walk test; type 1: obviously predominant emphysema in upper lung; type 2: somewhat predominant emphysema in upper lung; type 3: equal extent of emphysema in upper and lower lung; and type 4: somewhat predominant emphysema in lower lung. 
of that distribution to further characterizing the clinical severity of these patients.

Patients with COPD were classified according to a subjective heterogeneity analysis of upper versus lower lung distribution of pulmonary emphysema, using a visual scoring system first described by Chae et al. ${ }^{(18)}$ In their assessments of the regional heterogeneity of the distribution of emphysema, those authors found a significant correlation between the quantitative assessment (with a computer algorithm) and the visual assessment. They also found that there was a considerable interobserver agreement in the visual assessment. Therefore, visual assessment of the distribution of pulmonary emphysema could be a reliable method, with one major advantage, which is the fact that everyone can use it, especially when CT analysis software is not available.

Our results suggest that, among COPD patients with emphysema, there is greater COPD severity, defined as a higher degree of airflow obstruction and lower alveolar-capillary diffusing capacity, in those with predominantly lower-lung emphysema, whereas functional status is better in those with predominantly upper-lung emphysema. These results can be explained, in part, by the smaller area of the lung affected when emphysema is predominantly in the upper lobes.

Regarding the COPD patients with homogeneous emphysema (type 3), our data indicate a tendency toward higher hyperinflation, with a higher RV/TLC ratio (Figure 2), although the difference did not reach statistical significance. That is probably associated with the broader, more uniform distribution of parenchymal destruction, together with the fact had a median packyear smoking history was higher among the patients with type 3 emphysema distribution ( 60 pack-years vs. 40.5 pack-years for those with type 1 emphysema distribution; $p=0.012$ ).

After stratifying the study population according to the cut-off values for the assignment of at least 1 point on the Body mass index, airflow Obstruction,
Dyspnea, and Exercise capacity (BODE) index, ${ }^{(21)}$ which assesses the risk of death for COPD patients, we observed that type 4 emphysema distribution (slightly predominant in the lower lung) significantly increases the risk of severe airway obstruction $\left(\mathrm{FEV}_{1}<65 \%\right.$ of predicted) and reduced the 6MWD to $<350 \mathrm{~m}$ (Table 2). Hypoxemia was identified as another risk factor for mortality in COPD. ${ }^{(21,29)}$ Our results show that patients with emphysema that is slightly predominant in the lower lung are more likely to be hypoxemic.

Our findings are consistent with those of previous studies showing a strong association between lower-zone emphysema and airflow limitation. ${ }^{(18,19,30)}$ In another study, however, upper-zone predominance of emphysema was associated with a worse total St George's Respiratory Questionnaire score, although it was not significantly associate with $\mathrm{FEV}_{1}$ (\% of predicted).(17) Reports are also inconsistent concerning the relationship between diffusing capacity and regional differences in emphysema distribution. Gurney et al.(31) observed that DLCO is more strongly affected by lower-lung emphysema than by upper-lung emphysema, whereas Parr et al. ${ }^{(32)}$ found DLCO to be relatively preserved in patients with lower-lung emphysema. Those differences might be attributable to the different methods applied for assessing the regional distribution of emphysema.

The present study has a number of limitations. First, the female gender is not well represented in this study group. However, that is representative of the gender distribution of emphysema patients treated at our outpatient clinic. Second, our sample did not include any subjects with clearly lower lung-predominant emphysema (type 5). Because most of the patients were smokers, that type of emphysema distribution (sparing the upper lung) would be expected to be rather rare. We can presume that the clinical-radiological correlations for type 5 emphysema would be similar to those found for type 4 . In order to extrapolate our results, a larger study sample, with similar gender proportions and including all types of emphysema distribution, will be needed. Finally, some interobserver

Table 2. Distribution of pulmonary emphysema according to functional status and the respective functional severity.

\begin{tabular}{|c|c|c|c|c|}
\hline Variable & $\begin{array}{l}\text { Emphysema } \\
\text { distribution }\end{array}$ & $\begin{array}{c}\text { Frequency }^{\mathrm{a}} \\
\mathrm{n}(\%)\end{array}$ & $\begin{array}{l}\text { Adjusted } \text { OR }^{\mathrm{b}} \text { (95\% } \\
\text { CI) }\end{array}$ & p \\
\hline $\mathrm{FEV}_{1}<65 \%$ of predicted ${ }^{\mathrm{c}}$ & $\begin{array}{l}\text { Type } 1 \\
\text { Type } 2 \\
\text { Type } 3 \\
\text { Type } 4\end{array}$ & $\begin{array}{l}14(45.2 \%) \\
13(61.9 \%) \\
12(85.7 \%) \\
15(78.9 \%)\end{array}$ & $\begin{array}{c}1 \text { (reference) } \\
1.69(0.32-8.92) \\
5.79(1.06-31.64) \\
6.92(1.43-33.45)\end{array}$ & $\begin{array}{l}0.045^{*} \\
0.537 \\
0.043^{*} \\
0.016^{*}\end{array}$ \\
\hline $6 M W D<350 \mathrm{~m}^{\mathrm{c}}$ & $\begin{array}{l}\text { Type } 1 \\
\text { Type } 2 \\
\text { Type } 3 \\
\text { Type } 4 \\
\end{array}$ & $\begin{array}{l}1(3.6 \%) \\
2(9.5 \%) \\
3(21.4 \%) \\
9(52.9 \%) \\
\end{array}$ & $\begin{array}{c}1 \text { (reference) } \\
1.63(0.31-8.70) \\
5.58(1.01-30.84) \\
6.36(1.26-32.18)\end{array}$ & $\begin{array}{l}0.064 \\
0.567 \\
0.049^{*} \\
0.025^{*}\end{array}$ \\
\hline Hypoxemiad $^{d}$ & $\begin{array}{l}\text { Type } 1 \\
\text { Type } 2 \\
\text { Type } 3 \\
\text { Type } 4\end{array}$ & $\begin{array}{l}3(13.0 \%) \\
4(20.0 \%) \\
6(50.0 \%) \\
9(52.9 \%)\end{array}$ & $\begin{array}{c}1 \text { (reference) } \\
2.85(0.24-33.89) \\
7.60(0.67-86.19) \\
32.66(3.26-326.84)\end{array}$ & $\begin{array}{l}0.006^{*} \\
0.408 \\
0.102 \\
0.003^{*}\end{array}$ \\
\hline
\end{tabular}

6MWD: six-minute walk distance; type 1: obvious upper-lung predominance; type 2: slight upper-lung predominance; type 3: equal upper- and lower-lung extent; type 4: slight lower-lung predominance. ${ }^{a}$ Corresponds

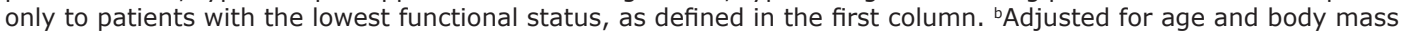
index. ${ }^{c}$ Cut-off value for the assignment of at least 1 point on the Body mass index, airflow Obstruction, Dyspnea, and Exercise capacity (BODE) index. ${ }^{\mathrm{d} D e f i n e d}$ as $\mathrm{PaO}_{2}<60 \mathrm{mmHg}$ with an $\mathrm{FiO}_{2}$ of 0.21 . ${ }^{*} \mathrm{p}<0.05$. 
variability is predictable, as previously noticed. $(18,33,34)$ Such disagreement can be seen primarily for patients with the least severe emphysema and with only partial upper or lower lung predominance. In fact, most discordant cases were related to classification differences between contiguous types.

In the past, direct visual observation and subjective visual grading were considered to have similar precision as the computer-assisted methods of emphysema quantification on CT scans. ${ }^{(35-39)}$ Although we have not provided a direct measure of emphysema severity, the purpose of this study was to present a qualitative (rather than quantitative), simple, affordable alternative method that could be widely used by clinicians to classify the heterogeneity of pulmonary emphysema.
In summary, in this group of COPD patients with pulmonary emphysema, lower lung-dominant distribution, as assessed by a subjective score, was found to have a significant impact on physiologic parameters, including pulmonary function test results and exercise capacity, although not on the clinical presentation of the disease, as assessed by the MMRC dyspnea scale score and the number of exacerbations in the last year. Further studies are warranted in order to confirm the importance of our findings.

\section{ACKNOWLEDGMENTS}

We thank Cristina Carrondo, Elisabete Santa Clara, Ermelinda Eusébio, Joana Pipa, Patrícia Dantas, Paulo Viana, and Teresa Santiago for performing the pulmonary function tests.

\section{REFERENCES}

1. Global Initiative for Chronic Obstructive Lung Disease [homepage on the Internet]. Bethesda: Global Initiative for Chronic Obstructive Lung Disease. [cited 2012 Dec 1]. Global Strategy for the Diagnosis, Management and Prevention of COPD--revised 2011. [Adobe Acrobat document, 90p.]. Available from: http://www.goldcopd.org/ uploads/users/files/GOLD_Report_2011_Feb21.pdf

2. de Torres JP, Bastarrika G, Zagaceta J, Sáiz-Mendiguren R, Alcaide $A B$, Seijo LM, et al. Emphysema presence, severity, and distribution has little impact on the clinical presentation of a cohort of patients with mild to moderate COPD. Chest. 2011;139(1):36-42. http:// dx.doi.org/10.1378/chest.10-0984

3. Celli BR. Roger s. Mitchell lecture. Chronic obstructive pulmonary disease phenotypes and their clinical relevance. Proc Am Thorac Soc 2006;3(6):461-6. http://dx.doi.org/10.1513/pats.200603-029MS

4. Marsh SE, Travers J, Weatherall M, Williams MV, Aldington S Shirtcliffe PM, et al. Proportional classifications of COPD phenotypes. Thorax. 2008;63(9):761-7. http://dx.doi.org/10.1136/thx.2007.089193

5. Boschetto P, Quintavalle S, Zeni E, Leprotti S, Potena A, Ballerin L, et al. Association between markers of emphysema and more severe chronic obstructive pulmonary disease. Thorax. 2006;61(12):103742. http://dx.doi.org/10.1136/thx.2006.058321

6. Boschetto $P$, Miniati M, Miotto D, Braccioni F, De Rosa E, Bonon I, et al. Predominant emphysema phenotype in chronic obstructive pulmonary. Eur Respir J. 2003;21(3):450-4.

7. O'Donnell DE, Revill SM, Webb KA. Dynamic hyperinflation and exercise intolerance in chronic obstructive pulmonary disease. Am J Respir Crit Care Med. 2001;164(5):770-7. http://dx.doi.org/10.1164/ ajrccm.164.5.2012122

8. Diaz O, Villafranca C, Ghezzo H, Borzone G, Leiva A, Milic-Emil J, et al. Role of inspiratory capacity on exercise tolerance in COPD patients with and without tidal expiratory flow limitation at rest Eur Respir J. 2000;16(2):269-75. http://dx.doi.org/10.1034/j.13993003.2000.16b14.x

9. Kent BD, Mitchell PD, McNicholas WT. Hypoxemia in patients with COPD: cause, effects, and disease progression. Int J Chron Obstruct Pulmon Dis. 2011;6:199-208.

10. Hayhurst MD, MacNee W, Flenley DC, Wright D, McLean A Lamb D, et al. Diagnosis of pulmonary emphysema by computed tomography. Lancet. 1984;2(8398):320-2. http://dx.doi.org/10.1016/ S0140-6736(84)92689-8

11. Müller NL, Staples CA, Miller RR, Abboud RT. "Density Mask". An objective method to quantitate emphysema using computed tomography. Chest. 1988;94(4):782-7. http://dx.doi.org/10.1378/ chest.94.4.782

12. Gould GA, Redpath AT, Ryan M, Warren PM, Best JJ, Flenley DC, et al. Lung CT density correlates with measurements of airflow limitation and the diffusing capacity. Eur Respir J. 1991;4(2):141-6.

13. Haraguchi M, Shimura S, Hida W, Shirato K. Pulmonary function and regional distribution of emphysema as determined by high-resolution computed tomography. Respiration. 1998;65(2):125-9. http://dx.doi. org/10.1159/000029243
14. Edwards MA, Hazelrigg S, Naunheim KS. The National Emphysema Treatment Trial: summary and update. Thorac Surg Clin 2009;19(2):169-85. http://dx.doi.org/10.1016/j.thorsurg.2009.02.007

15. Ingenito EP, Wood DE, Utz JP. Bronchoscopic lung volume reduction in severe emphysema. Proc Am Thorac Soc. 2008;5(4):454-60. http:// dx.doi.org/10.1513/pats.200707-085ET

16. Silverman EK, Sandhaus RA. Clinical practice. Alpha1-antitrypsin deficiency. N Engl J Med. 2009;360(26):2749-57. http://dx.doi. org/10.1056/NEJMcp0900449

17. Mair G, Miller JJ, McAllister D, Maclay J, Connell M, Murchison JT, et al. Computed tomographic emphysema distribution: relationship to clinical features in a cohort of smokers. Eur Respir J. 2009;33(3):53642. http://dx.doi.org/10.1183/09031936.00111808

18. Chae EJ, Seo JB, Song JW, Kim N, Park BW, Lee YK, et al. Slope of emphysema index: an objective descriptor of regional heterogeneity of emphysema and an independent determinant of pulmonary function. AJR Am J Roentgenol. 2010;194(3):W248-55. http://dx.doi. org/10.2214/AJR.09.2672

19. Nakano $Y$, Sakai H, Muro S, Hirai T, Oku Y, Nishimura K, et al Comparison of low attenuation areas on computed tomographic scans between inner and outer segments of the lung in patients with chronic obstructive pulmonary disease: incidence and contribution to lung function. Thorax. 1999;54(5):384-9. http://dx.doi.org/10.1136/ thx.54.5.384

20. Park KJ, Bergin CJ, Clausen JL. Quantitation of emphysema with three-dimensional CT densitometry: comparison with twodimensional analysis, visual emphysema scores, and pulmonary function test results. Radiology. 1999;211(2):541-7. http://dx.doi. org/10.1148/radiology.211.2.r99ma52541

21. Celli BR, Cote CG, Marin JM, Casanova C, Montes de Oca M, Mendez $R A$, et al. The body-mass index, airflow obstruction, dyspnea, and exercise capacity index in chronic obstructive pulmonary disease. N Engl J Med. 2004;350(10):1005-12. http://dx.doi.org/10.1056/ NEJMoa021322

22. Mahler DA, Wells CK. Evaluation of clinical methods for rating dyspnea. Chest. 1988;93(3):580-6. http://dx.doi.org/10.1378/ chest.93.3.580

23. Rodriguez-Roisin R. Toward a consensus definition for COPD exacerbations. Chest. 2000; 117(5 Suppl 2):398S-401S. http://dx.doi. org/10.1378/chest.117.5_suppl_2.398S

24. Burge S, Wedzicha JA. COPD exacerbations: definitions and classifications. Eur Respir J Suppl. 2003;41:46s-53s. http://dx.doi.org /10.1183/09031936.03.00078002

25. Celli BR, MacNee W; ATS/ERS Task Force. Standards for the diagnosis and treatment of patients with COPD: a summary of the ATS/ERS position paper. Eur Respir J. 2004;23(6):932-46. http:// dx.doi.org/10.1183/09031936.04.00014304

26. Roca J, Burgos F, Sunyer J, Saez M, Chinn S, Antó JM, et al References values for forced spirometry. Group of the European Community Respiratory Health Survey. Eur Respir J. 1998;11(6):135462. http://dx.doi.org/10.1183/09031936.98.11061354 
27. ATS Committee on Proficiency Standards for Clinical Pulmonary Function Laboratories. ATS statement: guidelines for the six-minute walk test. Am J Respir Crit Care Med. 2002;166(1):111-7. http:// dx.doi.org/10.1164/ajrccm.166.1.at1102

28. Webb WR. Radiology of obstructive pulmonary disease. AJR Am J Roentgenol. 1997;169(3):637-47. http://dx.doi.org/10.2214/ ajr.169.3.9275869

29. Continuous or nocturnal oxygen therapy in hypoxemic chronic obstructive lung disease: a clinical trial. Nocturnal Oxygen Therapy Trial Group. Ann Intern Med. 1980;93(3):391-8. http://dx.doi. org/10.7326/0003-4819-93-3-391

30. Saitoh T, Koba H, Shijubo N, Tanaka H, Sugaya F. Lobar distribution of emphysema in computed tomographic densitometric analysis. Invest Radiol. 2000;35(4):235-43. http://dx.doi.org/10.1097/00004424200004000-00004

31. Gurney JW, Jones KK, Robbins RA, Gossman GL, Nelson KJ, Daughton D, et al. Regional distribution of emphysema: correlation of high-resolution CT with pulmonary function tests in unselected smokers. Radiology. 1992;183(2):457-63. http://dx.doi.org/10.1148/ radiology.183.2.1561350

32. Parr DG, Stoel BC, Stolk J, Stockley RA. Pattern of emphysema distribution in alpha1-antitrypsin deficiency influences lung function impairment. Am J Respir Crit Care Med. 2004;170(8):1172-8. http:// dx.doi.org/10.1164/rccm.200406-7610C

33. Hersh CP, Washko GR, Jacobson FL, Gill R, Estepar RS, Reilly JJ, et al. Interobserver variability in the determination of upper lobepredominant emphysema. Chest. 2007;131(2):424-31. http://dx.doi. org/10.1378/chest.06-1040

34. Bankier AA, De Maertelaer V, Keyzer C, Gevenois PA. Pulmonary emphysema: subjective visual grading versus objective quantification with macroscopic morphometry and thin-section CT densitometry. Radiology. 1999;211(3):851-8. http://dx.doi.org/10.1148/ radiology.211.3.r99jn05851

35. Bergin C, Müller NL, Nichols DM, Lillington G, Hogg JC, Mullen $\mathrm{B}$, et al. The diagnosis of emphysema. A computed tomographicpathologic correlation. Am Rev Respir Dis. 1986;133(4):541-6.

36. Hruban RH, Mezian MA, Zerhouni EA, Khouri NF, Fishman EK, Wheeler PS, et al. High resolution computed tomography of inflation-fixed lungs. Pathologic-radiologic correlation of centrilobular emphysema. Am Rev Respir Dis. 1987;136(4):935-40. http://dx.doi org/10.1164/ajrccm/136.4.935

37. Miller RR, Müller NL, Vedal S, Morrison NJ, Staples CA. Limitations of computed tomography in the assessment of emphysema. Am Rev Respir Dis. 1989;139(4):980-3. http://dx.doi.org/10.1164/ ajrccm/139.4.980

38. Kuwano K, Matsuba K, Ikeda T, Murakami J, Araki A, Nishitani $H$, et al. The diagnosis of mild emphysema. Correlation of computed tomography and pathology scores. Am Rev Respir Dis. 1990;141(1):169-78. http://dx.doi.org/10.1164/ajrccm/141.1.169

39. Stern EJ, Frank MS. CT of the lung in patients with pulmonary emphysema: diagnosis, quantification, and correlation with pathologic and physiologic findings. AJR Am J Roentgenol. 1994;162(4):791-8. http://dx.doi.org/10.2214/ajr.162.4.8140992 